\title{
The effect of gamma radiation on plasma levels of zinc and selenium in nuclear medicine staff
}

\author{
Mahdiyeh Mirnam Niha, Mehdi Salehi Barough* \\ Department of Medical Radiation Engineering, Central Tehran Branch, Islamic Azad University, Tehran, Iran
}

*Corresponding Author: Mehdi Salehi Barough, Email: m.s.barough@gmail.com

\begin{abstract}
Background and aims: Gamma radiation is widely being used in medical-imaging centers. The aim of this study was to measure possible alterations in serum zinc and selenium levels among nuclear medicine staff.

Methods: This cross-sectional study was carried out on 30 nuclear medicine staff as well as on 10 individuals as the control group. Blood samples $(20 \mathrm{~mL}$ ) were obtained from the participants and the serum specimens were isolated by centrifugation at $4000 \mathrm{rpm}$ for 7 minutes. The samples were then used for measurement of zinc and selenium levels. Zinc and selenium levels were measured using atomic absorption spectroscopy (AAS) with a graphite furnace. The mean serum levels of zinc and selenium were compared using SPSS.

Results: The mean level of zinc in the radiated group $(70.91 \pm 14.46 \mu \mathrm{mol} / \mathrm{L})$ was significantly lower than that in the control group $(89.75 \pm 17.35 \mu \mathrm{mol} / \mathrm{L})(P=0.002)$. A negative significant correlation was found between the duration of exposure to radiation and zinc levels $(P=0.005)$. Furthermore, a negative significant relationship was observed between the mean radiation dose after 5 years and zinc concentration $(P=0.019)$. Non-significant difference was found in the mean level of selenium between control $(1.71 \pm 0.35 \mu \mathrm{mol} / \mathrm{L})$ and radiation $(2.13 \pm 1.12 \mu \mathrm{mol} / \mathrm{L})$ groups. Furthermore, no significant correlation was found between selenium level and exposure time. Conclusion: Based on the results, declined level of zinc can be considered as one of the possible mechanisms caused by gamma radiation on cells which may be associated with oxidative damage. Therefore, zinc therapy can be helpful for those who work at medical radiation centers; however, it merits further studies.

Keywords: Gamma; Serum; Zinc; Selenium
\end{abstract}

Received: 2 October 2017, Accepted: 21 February 2018, ePublished: 13 April 2018

\section{Introduction}

Live organisms are nowadays exposed to numerous radiation sources, including nuclear testing, nuclear products, and medical treatments in the medical centers. This exposure to radiation exerts many destructive effects on cells. The ionizing radiation, through the excitement of atoms and molecules, leads to irreversible damage to cells, which vary in size depending on radiation dose and duration $(1,2)$.

Recent investigations have found that high energy of ionizing radiation such as gamma rays generates highly reactive radicals, such as hydroxyl free radicals $\left(\mathrm{OH}^{\circ}\right)$, from breaking up of water molecules inside the cell that has a high destructive effect on cells (3-5). In view of the fact that these radicals have unpaired electrons, then they are highly reactive and easily attack cellular macromolecules such as lipids, proteins, DNA, and enzymes which cause severe cell damage and cell death (3). However various studies have highlighted the destructive effects of gamma rays on the body, though its molecular mechanisms are not well-known yet. It seems that evacuation or reduction in the concentration of some of the essential elements of the body accounts for one of the possible mechanisms of the destructive effects of gamma rays on cells, among which the role of zinc and selenium is of great importance (4).

Zinc is one of the essential elements in the body, which not only has a high antioxidant property but is vital for the function of many proteins, including metalloenzyme and zinc-finger protein, which is highly demanded for zinctranscriptional factors $(6,7)$. A number of previous studies have shown that zinc is required for many physiological processes including growth, neuronal function, reproduction, and immune system (5). Zinc deficiency, in this regard, has been implicated in a wide range of diseases, including immune system disorders, lymphopenia, intrinsic immunity, and increased infectious diseases $(8,9)$. Selenium is the other essential element demanded for the body. It plays a very leading role in collecting reactive oxygen species (ROS), while it contributes as a co-factor to the structure of glutathione peroxidase (GPX), which is an antioxidant enzyme (7). Considering the very important antioxidant properties of zinc and selenium as well as the effects of gamma irradiation on oxidative stress, it seems that reduction in the concentration of these elements can be considered as one of the factors driving the destructive effects of gamma rays on the body. Given the importance 
of zinc and selenium, their measurement can therefore provide useful information about normal metabolic reactions to ionizing radiation in the body.

For example, studies in individuals exposed to low $\mathrm{X}$-radiation doses have shown a significant relationship between levels of blood elements and structural changes in hair and nails (6). In addition, studies in animals exposed to $\mathrm{X}$-rays and gamma rays indicate a change in plasma and tissue levels of detectable elements $(10,11)$. So far, limited studies have investigated the effects of these radiations, in particular, gamma rays on plasma levels of zinc and selenium in Iran and in most parts of the world, especially in individuals who are in constant contact with gamma rays; the results of those studies are somewhat contradictory. The studies of Shahbazi-Ghahrouei et al (2) and Ebrahiminia et al (12) are such examples. ShahbaziGhahrouei et al showed that chronic radiation can disturb the absorption and excretion mechanisms by reducing the concentration of some essential elements of the body, especially zinc, copper, iron, and magnesium. The authors observed a significant decrease and a significant increase in zinc and copper concentrations, respectively, in the serum of the radiology and radiotherapy workers, while they did not observe any significant difference in the concentration of iron and magnesium elements (2). Given the fact that nuclear medicine experts are always in contact with low doses of gamma radiation, the aim of this study was to investigate the possible changes of zinc and selenium elements in serum samples of nuclear medicine experts. In this regard, this study may increase knowledge about the effect of radiation on essential elements and their physiological outcomes on the human body on one hand and suggestion of solutions to counteract and treat it on the other hand.

\section{Materials and Methods}

This cross-sectional study was carried out on 30 radiologists who had at least 5 years of work experience, as well as on 10 subjects (as control group) who were not exposed to radiation, during the spring and summer of 2017 at the Baqiyatallah Hospital, Tehran. Sample size was calculated based on previous studies (10). The subjects in both control and radiation groups were similar in age (28-68 years), gender (60\% male and $40 \%$ female), and weight $(55-100 \mathrm{~kg})$. Before the study, a questionnaire containing demographic information of the individuals, the history of a specific illness, the use of drugs or the use of certain drugs was prepared and completed by the subjects. The members of the radiation group were selected based on the following criteria: 1 ) the history of exposure to gamma rays; 2) the specific radiation dose received; 3) those working in the nuclear medicine department who had a direct association with gamma radiation; and 4) those who entered the study with personal consent. People who were taking zinc or selenium supplements were excluded from the study. The subjects completed and signed an informed consent form. About $20 \mathrm{~mL}$ of peripheral blood samples were obtained from the subjects in both groups, according to a standard method. The blood serums were then separated by centrifugation (EBA21, Hettich, Germany) at $4000 \mathrm{rpm}$ for 7 minutes, transferred to 15 $\mathrm{mL}$ falcons, and stored for further experiments at $20^{\circ} \mathrm{C}$. Zinc and selenium concentrations were measured using atomic absorption spectrometry (AAS) with graphite furnace (GBC-GF500, Australia). To measure the zinc, $0.1 \mathrm{~mL}$ of $\mathrm{HCl}$ solution was added to $1 \mathrm{~mL}$ of serum sample to reach a volume of $5 \mathrm{~mL}$ and then the solution was centrifuged at $7000 \mathrm{rpm}$ for 2 minutes. To measure the selenium element, trichloroacetic acid was applied to the sediment of macromolecules and proteins. Then, the supernatant was removed and the injectable device and and the concentration of desired element was measured. Measurements were performed 5 times for all specimens. The results of this study were analyzed using SPSS software (version 22.0). The mean of quantitative data was analyzed using descriptive test and indicated as mean $\pm \mathrm{SD}$. Crosstabs were used to determine the percentage and number of parameters. Chi-square test was used to compare the number or percentage of parameters between the two groups. In addition, $t$ test was used to compare the mean of data including the concentration of elements between the control and radiation groups. The relationship between the concentration of the elements and other parameters was investigated by Pearson $\mathrm{r}$ correlation. In this study, the $P$ value less than 0.05 was considered statistically significant.

\section{Results}

The demographic data of the two control and radiation groups are summarized in Table 1 . The mean age of the subjects in the control and the radiation groups was $37.37 \%$ and $41.83 \pm 10.38 \%$, respectively. There was no significant difference between the two groups $(P=$ 0.171 ) regarding their age. In both groups, approximately $40 \%$ were female and $60 \%$ were male. Moreover, there was no significant difference in mean weight between the two groups $(P=0.29)$. The mean exposure time in the radiation group was $6.76 \pm 2.04$ years and the radiation dose after 5 years was $21.63 \pm 18.61$ millisieverts. There was no significant difference between the two groups in terms of other parameters, including smoking, use of illicit drugs, and exercise.

In the control group, however, $20 \%$ had alcohol addiction, which was significantly different from the radiation group $(P=0.012)$. Furthermore, there was a significant difference in milk intake between the two groups $(P=0.01)$. In one study conducted in Egypt, $90 \%$ of the control people were using daily milk, while only $43.33 \%$ of the subjects in the radiation group had a habit of daily milk consumption (Table 1). Information on the 
Table 1. Demographic data of the control and radiation groups

\begin{tabular}{|c|c|c|c|}
\hline Parameters & $\begin{array}{l}\text { Control group } \\
(n=10)(25 \%)\end{array}$ & $\begin{array}{l}\text { Radiation group } \\
(\mathrm{n}=30)(75 \%)\end{array}$ & $P$ value \\
\hline Age $(y)$ & $37.0 \pm 5.77$ & $41.83 \pm 10.38$ & 0.171 \\
\hline Sex & & & 0.85 \\
\hline Male & $6(60)$ & $17(56.66)$ & \\
\hline Female & $4(40)$ & $13(43.33)$ & \\
\hline Weight (kg) & $79.9 \pm 6.43$ & $75.36 \pm 12.83$ & 0.293 \\
\hline Exposure time $(y)$ & - & $6.76 \pm 2.04$ & - \\
\hline $\begin{array}{l}\text { Radiation dose after } 5 \\
\text { years (millisievert) }\end{array}$ & - & $21.63 \pm 48.61$ & - \\
\hline Smoker & & & 0.058 \\
\hline Yes & $3(30)$ & $2(6.63)$ & \\
\hline No & $7(70)$ & $28(93.33)$ & \\
\hline Alcohol consumption & & & 0.012 \\
\hline Yes & $2(20)$ & - & \\
\hline No & $8(80)$ & $30(100)$ & \\
\hline Use of illicit drugs & & & 0.4 \\
\hline Yes & 0 & $2(6.33)$ & \\
\hline No & $10(80)$ & $28(93.33)$ & \\
\hline Exercise & & & 0.27 \\
\hline Yes & $4(40)$ & $18(60)$ & \\
\hline No & $6(60)$ & $12(40)$ & \\
\hline Milk consumption & & & 0.01 \\
\hline Yes & $9(90)$ & $13(43.33)$ & \\
\hline No & $1(10)$ & $17(56.66)$ & \\
\hline
\end{tabular}

history of specific diseases such as heart disease, thyroid dysfunction, hypertension, cancer, digestive problems, hyperlipidemia, anemia, diabetes, and skin diseases in two groups of control and radiation are summarized in Table 2. There was no significant difference between the two groups in terms of the history of the disease. The mean concentrations of zinc and selenium in the control and radiation groups are shown in Table 3. The mean concentrations of zinc in the control and radiation groups were $89.75 \pm 17.35 \mu \mathrm{mol} / \mathrm{L}$ and $70.91 \pm 14.46 \mu \mathrm{mol} / \mathrm{L}$, respectively, which were significantly different $(P=0.002)$. No significant difference was observed in the mean concentrations of selenium in the control and radiation groups $(P=0.34)$.

Furthermore, in this study the mean concentrations of zinc and selenium were compared between male and female groups as shown in Table 4. Male and female groups were not significantly different regarding mean levels of zinc $(P=0.6)$ and selenium $(P=0.74)$. An inverse significant correlation was observed between the zinc concentration and the duration of exposure to radiation. Hence, the long-term radiation exposure was significantly associated with lower zinc levels $(P=0.005)$ (Figure 1). No significant correlation was found between the concentration of selenium element and the duration of exposure to radiation $(P=0.71)$.

Moreover, the concentration of these elements was analyzed regarding the radiation dose in 5 years. The
Table 2. Disease records of control and radiation groups

\begin{tabular}{|c|c|c|c|}
\hline Parameters & $\begin{array}{l}\text { Control group } \\
(n=10)(25 \%)\end{array}$ & $\begin{array}{c}\text { Radiation group } \\
(n=30)(75 \%)\end{array}$ & $P$-value \\
\hline Heart disease & & & 0.4 \\
\hline Yes & 0 & $2(6.66)$ & \\
\hline No & $10(100)$ & $28(93.33)$ & \\
\hline Thyroid disorder & & & 0.16 \\
\hline Yes & 0 & $5(16.66)$ & \\
\hline No & $10(100)$ & $25(83.33)$ & \\
\hline Increased blood pressure & & & 0.16 \\
\hline Yes & 0 & $5(16.66)$ & \\
\hline No & $10(100)$ & $25(83.33)$ & \\
\hline Cancer & & & - \\
\hline Yes & 0 & 0 & \\
\hline No & $10(100)$ & $30(100)$ & \\
\hline Digestive problems & & & 0.29 \\
\hline Yes & 0 & $3(10)$ & \\
\hline No & $10(100)$ & $27(90)$ & \\
\hline Hyperlipidemia & & & 0.6 \\
\hline Yes & $2(20)$ & $4(13.33)$ & \\
\hline No & $8(80)$ & $26(86.66)$ & \\
\hline Anemia & & & 0.4 \\
\hline Yes & 0 & $2(6.66)$ & \\
\hline No & $10(100)$ & $28(93.33)$ & \\
\hline Diabetes & & & 0.29 \\
\hline Yes & 0 & $3(10)$ & \\
\hline No & $10(100)$ & $27(90)$ & \\
\hline Skin diseases & & & 0.079 \\
\hline Yes & $1(10)$ & 0 & \\
\hline No & $9(90)$ & $30(100)$ & \\
\hline
\end{tabular}

Table 3. Zinc and selenium concentrations in the blood serums of control and radiation subjects

\begin{tabular}{lccc}
\hline Parameters & $\begin{array}{c}\text { Control group } \\
(\mathbf{n}=\mathbf{1 0})\end{array}$ & $\begin{array}{c}\text { Radiation group } \\
(\mathbf{n}=\mathbf{3 0})\end{array}$ & $\boldsymbol{P}$ value \\
\hline Zinc $(\mu \mathrm{mol} / \mathrm{L})$ & $89.75 \pm 17.35$ & $70.91 \pm 14.46$ & 0.002 \\
Selenium $(\mu \mathrm{mol} / \mathrm{L})$ & $1.71 \pm 0.35$ & $2.13 \pm 1.12$ & 0.34 \\
\hline
\end{tabular}

Table 4. Zinc and selenium concentrations in blood serums of men and women

\begin{tabular}{lccc}
\hline Parameters & $\begin{array}{c}\text { Male group } \\
\mathbf{2 3} \mathbf{( 7 6 . 6 6 )}\end{array}$ & $\begin{array}{c}\text { Female group } \\
\mathbf{1 7}(\mathbf{5 6 . 6 6})\end{array}$ & $\boldsymbol{P}$ value \\
\hline Zinc $(\mu \mathrm{mol} / \mathrm{L})$ & $76.84 \pm 17.32$ & $73.97 \pm 17.24$ & 0.6 \\
Selenium $(\mu \mathrm{mol} / \mathrm{L})$ & $1.96 \pm 0.93$ & $2.1 \pm 1.1$ & 0.74 \\
\hline
\end{tabular}

results showed that there was a significant inverse association between the radiation dose after 5 years $(P=$ 0.019 ) and zinc concentration (Figure 2). However, no significant correlation was found between the radiation dose after 5 years and the concentration of selenium $(P=$ 0.52 ). The relationship between mean concentrations of zinc and selenium and other demographic parameters as well as disease history was also investigated. A significant 


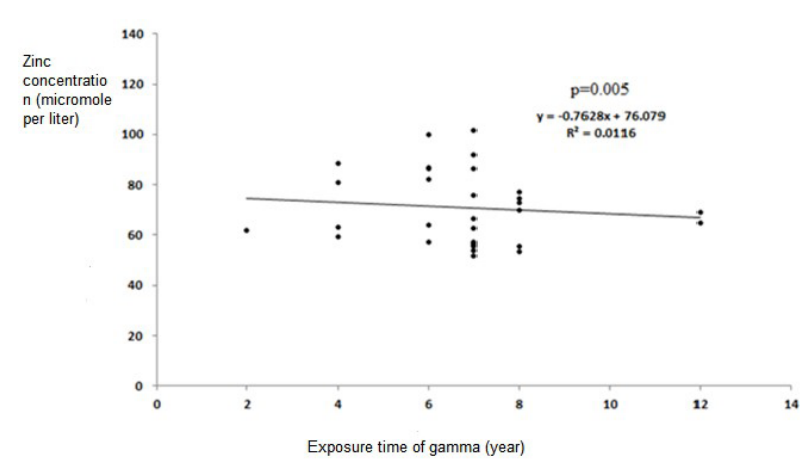

Figure 1. Relationship between exposure time to gamma rays and zinc concentration

Note: There was an inverse significant correlation between zinc concentration and exposure to radiation $(P=0.005)$.

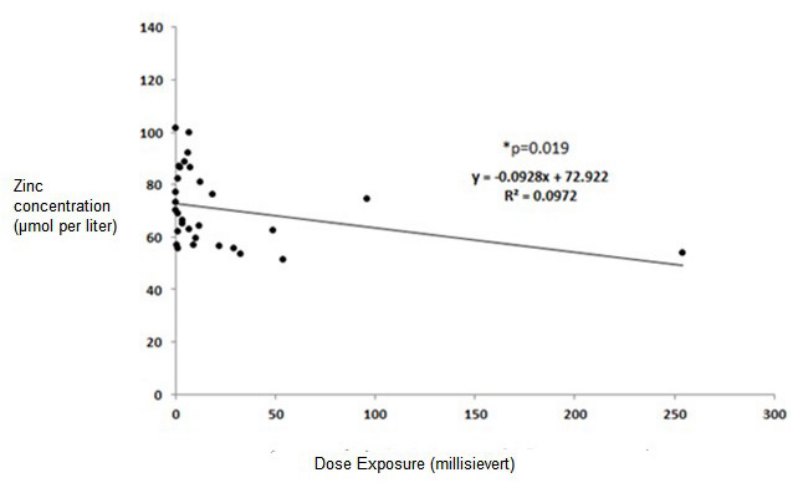

Figure 2. Relationship between exposure time to gamma rays over 5 years and zinc concentration

Note: There was an inverse significant relationship between zinc concentration and exposure to radiation after 5 years $(P=0.019)$.

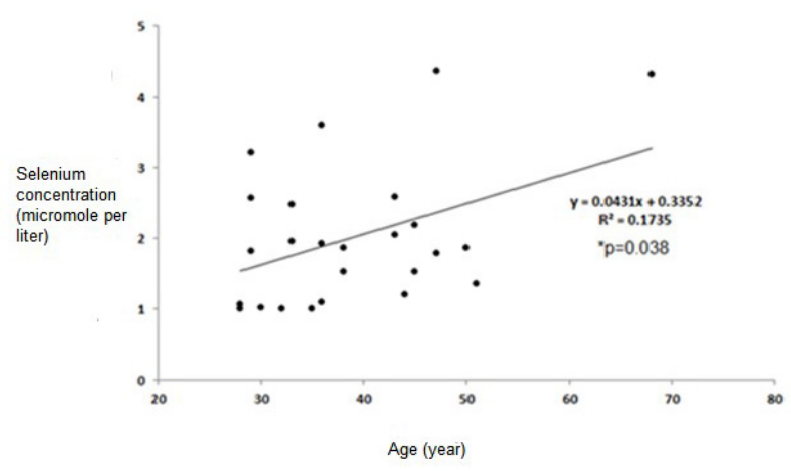

Figure 3. Relationship between age and selenium concentration. Note: There was a significant positive correlation between age and selenium concentration $(P=0.038)$.

positive correlation $(P=0.038)$ was found between selenium concentration and age in the subjects (Figure 3), so that selenium concentration was higher in blood serums of older subjects. While, no relationship was observed between age and zinc concentration. Although no significant correlation was seen between zinc and selenium concentrations and other parameters, there was a significant difference in zinc concentration between the subjects with thyroid problem $(61.5 \pm 11.86)$ and those with no thyroid problem $(77.64 \pm 16.99)(P=0.047)$.

\section{Discussion}

In this study, the first effect of gamma radiation on plasma levels of zinc and selenium was investigated in the staff of the Nuclear Medicine Department. Although there was no significant difference in the concentration of selenium between the two groups of radiation and control, the results of our study indicated that the concentration of zinc element in the blood serum of staff under radiation was significantly lower than that of control subjects. An increased exposure to gamma rays was inversely and significantly associated with a decrease in zinc concentrations. Such finding was also found for gamma radiation exposure after 5 years. So far, very limited studies have investigated the effect of radiation on the serum concentration of elements, especially zinc and selenium, among nuclear medical staff, and most studies have considered these effects in vivo and in vitro (on different cell lines). In a study by ShahbaziGahrouei et al, the association of chronic radiation with the concentrations of copper, zinc, iron, and magnesium in the blood serum of hot springs workers in Mahalat, Iran, was studied. According to the results of the study, chronic radiation could disturb the absorption and excretion mechanisms by reducing the concentration of some essential elements of the body, viz zinc, copper, iron, and magnesium (2). In another study, Ebrahiminia et al (12) examined the association of chronic radiation with the concentrations of zinc, copper, iron, and magnesium. The results of this study showed a significant decrease and a significant increase in the concentrations of zinc and copper, respectively, in blood serum of radiology and radiotherapy workers. However, there was no significant difference in the concentrations of iron and magnesium elements.

Several studies have also examined the effects of gamma rays in vivo and in vitro on a variety of cell lines. For example, in a study by Ono et al, the effect of gamma rays was investigated on the level of metallothionein, lipid peroxidation, and zinc in the brains of rats (13). The results of their study showed that increased dosage of radiation significantly reduced the total zinc concentration in the brains of rats, but no significant changes were observed in lipid peroxidation level. Since the metallothionein concentration was significantly increased, the researchers suggested that increased levels of metallothionein as an important intracellular antioxidant probably played an important role in inhibiting lipid peroxidation (13).

Furthermore, several studies have investigated the increase of free radicals especially ROS, oxidative stress, and a reduction in life cycle of the cell as the main mechanisms of action of gamma rays on cells $(14,15)$. For example, in a study, Mishra showed that gamma rays lead to oxidative stress by increasing the level of intracellular ROS and 
subsequently inducing apoptosis or cell death (16). In another study by Vucic et al, gamma rays inhibited DNA synthesis, cell proliferation, and cytotoxic effects of cell. However, after 24, 48, and 72 hours, a significant increase (3 to 3.5 times) was seen in the expression level of the antioxidant enzymes of $\mathrm{Cu} / \mathrm{ZnSOD}$ and MnSOD (17). These results indicate that an increase in the expression level of antioxidant enzymes such as SOD plays an important role in reducing the harmful effects of gamma rays. Since zinc is an essential component in the structure of the SOD enzyme, a decrease in the level of zinc element found in our study can further provide the conditions for the destructive effects of gamma rays. Regarding the results of our study, it seems that a decrease in the level of zinc can be considered as another possible mechanism for the destructive effects of gamma rays on cells. The zinc element plays an important role not only in a variety of cell functions and processes, but also as a major component of the SOD structure and as an important antioxidant, it plays a role in protecting cells against the types of proteins that are involved in DNA synthesis, the transcription of genes, the structure of zip proteins, and cell proliferation under the effect of free radicals. Therefore, considering the antioxidant properties of zinc, the reduced serum levels of zinc can lead to increased levels of free radicals, oxidative stress, DNA damage, and ultimately cell death. Several studies have shown a correlation between the decrease in zinc level and an increase in the level of oxidative stress, oxidative damage, and cell death $(1,18-20)$.

\section{Conclusion}

In this study, the concentration of zinc in the blood serums of staff under radiation was lower than that of normal people. Further, an inverse relationship of radiation exposure and the exposure after 5 years with zinc concentration was observed. The results of this study indicated that probably one negative effect of gamma ray on cells is exerted by reducing the zinc level, which can be accompanied by an increase in oxidative damage. Given the very important role of zinc in the body and intracellular processes, the consumption of zinc supplements by people who are exposed to gamma rays is recommended. However, further studies are required on wider sample sizes in this regard.

Conflict of Interests

None.

Ethical considerations

This study was approved by the Ethics Committee of Baqiyatallah University of Medical Sciences (Code of Ethics: ir.bmsu. rec.1395.390).

\section{Acknowledgement}

This paper was extracted from the dissertation of Mahdiyeh Mirnam Niha, student at Central Branch, Tehran Azad University, Department of Medical Radiation Engineering (registration number 2331802, dated 15/12/2016).
References

1. Colagar AH, Marzony ET, Chaichi MJ. Zinc levels in seminal plasma are associated with sperm quality in fertile and infertile men. Nutr Res. 2009;29(2):82-8. doi: 10.1016/j. nutres.2008.11.007.

2. Shahbazi-Gahrouei D, Abdolahi M. Investigation of association between high background radiation exposure with trace element concentrations' (Copper, Zinc, Iron and Magnesium) of hot springs workers blood in Mahalat. Iran South Med J. 2014;17(4):687-94.

3. Basu B, Apte SK. Gamma radiation-induced proteome of Deinococcus radiodurans primarily targets DNA repair and oxidative stress alleviation. Mol Cell Proteomics. 2012;11(1):M111.011734. doi: 10.1074/mcp.M111.011734.

4. Kim DY, Hong MJ, Park CS, Seo YW. The effects of chronic radiation of gamma ray on protein expression and oxidative stress in Brachypodium distachyon. Int J Radiat Biol. 2015;91(5):407-19. doi: 10.3109/09553002.2015.1012307.

5. Skalny AA, Tinkov AA, Medvedeva YS, Alchinova IB, Karganov $M Y$, Skalny AV, et al. Effect of short-term zinc supplementation on zinc and selenium tissue distribution and serum antioxidant enzymes. Acta Sci Pol Technol Aliment. 2015;14(3):269-76. doi: 10.17306/j.afs.2015.3.28.

6. Majumdar S, Chatterjee J, Chaudhuri K. Ultrastructural and trace metal studies on radiographers' hair and nails. Biol Trace Elem Res. 1999;67(2):127-38.

7. Michalska-Mosiej M, Socha K, Soroczynska J, Karpinska E, Lazarczyk B, Borawska MH. Selenium, Zinc, Copper, and Total Antioxidant Status in the Serum of Patients with Chronic Tonsillitis. Biol Trace Elem Res. 2016;173(1):30-4. doi: 10.1007/s12011-016-0634-2.

8. Deletioglu V, Tuncay E, Toy A, Atalay M, Turan B. Immunospin trapping detection of antioxidant/pro-oxidant properties of zinc or selenium on DNA and protein radical formation via hydrogen peroxide. Mol Cell Biochem. 2015;409(1-2):23-31. doi: 10.1007/s11010-015-2508-x.

9. Wang F, Li Y, Cao Y, Li C. Zinc might prevent heat-induced hepatic injury by activating the Nrf2-antioxidant in mice. Biol Trace Elem Res. 2015;165(1):86-95. doi: 10.1007/s12011015-0228-4.

10. Cengiz M, Gurkaynak M, Vural H, Aksoy N, Cengiz B, Yildiz F, et al. Tissue trace element change after total body irradiation. Nephron Exp Nephrol. 2003;94(1):e12-6. doi: 10.1159/000070814.

11. Zhang X, Miao Y, Hu X, Min R, Liu P, Zhang H. Gamma Radiation-Induced Damage in the Zinc Finger of the Transcription Factor IIIA. Bioinorg Chem Appl. 2016;2016:1642064. doi: 10.1155/2016/1642064.

12. Ebrahiminia A, Shahbazi-Gahrouei D, Karegar A, Farzan A. Relationship between occupational exposure and concentration of some trace elements in radiology and radiotherapy workers. The Journal of Qazvin University of Medical Sciences. 2008;12(3):52-7.

13. Ono $S$, Cai L, Cherian MG. Effects of gamma radiation on levels of brain metallothionein and lipid peroxidation in transgenic mice. Radiat Res. 1998;150(1):52-7.

14. Dal-Pizzol F, Ritter C, Klamt F, Andrades M, da Frota ML Jr, Diel C, et al. Modulation of oxidative stress in response to gamma-radiation in human glioma cell lines. J Neurooncol. 2003;61(2):89-94.

15. Mortazavi S, Niroomand-Rad A, Roshan-Shomal P, RazaviToosi S, Mossayeb-Zadeh M, Moghadam M. Does shortterm exposure to elevated levels of natural gamma radiation in Ramsar cause oxidative stress? Int J Appl Basic Med Res. 2014;4(2):72-6. doi: 10.4103/2229-516x.136778. 
16. Mishra KP. Cell membrane oxidative damage induced by gamma-radiation and apoptotic sensitivity. J Environ Pathol Toxicol Oncol. 2004;23(1):61-6.

17. Vucic V, Isenovic ER, Adzic M, Ruzdijic S, Radojcic MB. Effects of gamma-radiation on cell growth, cycle arrest, death, and superoxide dismutase expression by DU 145 human prostate cancer cells. Braz J Med Biol Res. 2006;39(2):227-36. doi: / S0100-879x2006000200009.

18. Seth R, Corniola RS, Gower-Winter SD, Morgan TJ Jr, Bishop $\mathrm{B}$, Levenson CW. Zinc deficiency induces apoptosis via mitochondrial p53- and caspase-dependent pathways in human neuronal precursor cells. J Trace Elem Med Biol. 2015;30:59-65. doi: 10.1016/j.jtemb.2014.10.010.

19. Sorensen MB, Bergdahl IA, Hjollund NH, Bonde JP, Stoltenberg $\mathrm{M}$, Ernst E. Zinc, magnesium and calcium in human seminal fluid: relations to other semen parameters and fertility. Mol Hum Reprod. 1999;5(4):331-7.

20. Zhu B, Wang J, Zhou F, LiuY, Lai Y, Wang J, et al. Zinc Depletion by TPEN Induces Apoptosis in Human Acute Promyelocytic NB4 Cells. Cell Physiol Biochem. 2017;42(5):1822-36. doi: 10.1159/000479539. 